\title{
Reliability and Validity of a Japanese Version of 'Attitudes Towards the Elderly' Scale
}

\author{
SHIMPACHIRO OGIWARA, RPT, SRP(UK), ONC(UK), MCPA(C), BPT (C), MA(USA), PhD(USA) ${ }^{1)}$, \\ KATSUMI INOUE, BSc, MSc ${ }^{1)}$, SAYUKI KOSHIMIZU, BHSc, RPT ${ }^{2}$ \\ 1)Division of Rehabilitation Science, Department of Health Sciences, Graduate School for \\ Health Studies, The University of Kanazawa: 11-80 Kodatsuno 5, Kanazawa, Ishikawa \\ 920-0942, Japan. TEL +81 76-265-2616, FAX +81 76-234-4351, \\ E-mail:oggy@mhs.mp.kanazawa-u.ac.jp \\ ${ }^{2)}$ Keio University Tsukigase Rehabilitation Centre
}

\begin{abstract}
This paper describes the results of a study that examined the reliability and validity of a Japanese version of Kogan's Scale of Attitudes Towards the Elderly (ATE). The ATE scale measures the affective attitude component towards the elderly and contains 17 paired positive and negative statements to be responded to in a six-point range, from strongly agree to strongly disagree. A convenience sample of 314 practising physiotherapists in Ishikawa Prefecture, Japan, participated in this study, and data were collected by means of a mailed ATE questionnaire. The reliability of the scale was assessed as homogeneity, and its validity as construct validity. The rate of return was $57.3 \%$, of which the number of men was $79(43.9 \%)$ and women $101(56.1 \%)$. The mean (SD) number of years of the respondents' clinical experience was 8.9 (7.3) ranging from 0.5 to 37.9. All of the 34 items were found to have significant item-to-total correlations $(\mathrm{p}<0.01)$. The Cronbach's alpha reliability estimates for the total scale, positive items and negative items were $0.87,0.86$ and 0.85 , respectively. Some evidence for construct validity was found in the three-factor solution, which explained $30.7 \%$ of the variances. The factors derived from Spearman's rank correlation and factor analysis were 'prejudice,' 'appreciation,' and 'expectation,' with the rate of contribution (Cronbach's alpha) being 14.0\% (0.84), 8.7\% (0.77), and 8.0\% (0.74), respectively. The result of a multiple regression analysis indicated that neither the amount of clinical practice, the gender nor cohabitation with the elderly had any influence on the ATE of the respondents. This precluded the verification of convergent validity. From the results of this current study group, the Japanese version of the ATE scale can be considered a reliable and valid measure of documenting trends of importance for the care of the elderly.
\end{abstract}

Key words: Attitudes, Elderly, Scale testing

(This article was submitted Jul. 28, 2006, and was accepted Sep. 19, 2006)

\section{INTRODUCTION}

Japan has the fastest growing elderly population in the world, followed by Italy $(18.25 \%$ in 2001$)$, Germany $(17.1 \%$ in 2001$)$ and France $(16.1 \%$ in $2003)^{1)}$; Japan has indeed become a de facto ageing society. This has brought about the so-called "year 2007 problem," consequential issues resulting from the retirement of the baby boomers. Healthcare and welfare needs of the elderly are now enormous matters of concern in Japanese society. Importance of attitudes towards the elderly (ATE) as a research theme on the elderly becomes apparent when we view the above factors.

Attitudes are conceptualised as feelings, knowledge, and readiness to act, all of which are amenable to change. These concepts are considered important when applied to professional practice and 
in the education of physiotherapists.

As a research tool for the ATE, various scales have been used in the past; they are, for example, the 96-item version of the Tuckman-Lorge Scale ${ }^{2}$, the semantic differential as presented by Eisdorfer and Altrocchi ${ }^{3)}$, and the 34-item Attitude Toward Old People Scale developed by Kogan ${ }^{4}$, to name only a few. The Kogan's tool has been found to possess high reliability and validity values ${ }^{4}$. Subsequently, a Swedish version of Kogan's scale was introduced in $1987^{5}$ ) and a Japanese version in $2001^{6)}$.

Psychometric measures must possess high reliability and validity, and instruments are also needed that are standardized and well-tested to study ATE. Although high reliability and validity have been established for the Swedish version of Kogan's scale ${ }^{7)}$, there has not, until now, been any verification of the Japanese version. Hence, an attempt was made to test the reliability and validity of the Japanese version and verify its use through recruitment of physiotherapists to answer a survey. Verification of the ATE scale through this study would therefore be conducive to future research of ATE. Consequently, it could be used as a measurement of ATE for both students and practising physiotherapists, as well as other healthcare professionals in Japan.

\section{METHODOLOGY}

\section{Instrumentation}

Kogan's scale consists of one set of 17 statements expressing positive sentiments $\left(\mathrm{E}^{+}\right)$ about the elderly and a second set of 17 statements expressing negative sentiments $\left(\mathrm{E}^{-}\right)$. The manifest contents of these statements are as follows ${ }^{4}$. Items 1,5 and 12 are all concerned with the residential aspects of elderly persons' lives with special reference to segregation, maintenance of home, and character of neighbourhood, respectively. Items 2 and 8 reflect the degree to which vague feelings of discomfort and tension are experienced in the company of the elderly. Items 11 and 13 tap the extent to which the elderly differ among themselves. The nature of interpersonal relations across age generations - conflicted or benign - is implied in Items 9, 10, and 16. The theme of dependence is represented by Items 4 and 17. Items 3 and 6 refer to the cognitive style and competency of the elderly. Qualities of the elderly with respect to personal appearance and personality are cited in Items 14 and 15. Finally, Item 7, on socioeconomic power, does not readily cluster with any of the other items.

The scale is designed as a summed Likert attitude scale with six response categories provided for all of the items: strongly disagree, disagree, slightly disagree, slightly agree, agree, and strongly agree. These categories were scored 1, 2, 3, 5, 6, and 7, respectively, with a score of 4 assigned in the rare case of failure to respond to an item ${ }^{4}$. A high score for $\mathrm{E}^{+}$and low score for $\mathrm{E}^{-}$indicated favourable attitudes towards the elderly.

Kogan's original scale had item-to-total correlations among American college students in the range of $0.1-0.7^{4)}$. For the Swedish version, the coefficient alpha $(\alpha)$, also called Cronbach's alpha after Lee Cronbach ${ }^{8)}$, for the total scale was 0.79 . Also, strong evidence for construct validity was shown in the scale's capability to differentiate between individuals who preferred to work with the elderly rather than with young clients ${ }^{7)}$.

The authors also enquired about cohabitation of respondents with the elderly including their grandparent(s) to examine the possible effect of this on their ATE.

\section{Participants and procedures}

Out of the total physiotherapy membership of 373 in Ishikawa Prefecture, 314 practising physiotherapists were selected from the 2004 membership directory of the Ishikawa Physical Therapy Association. All the members were working in hospitals, clinics or nursing homes. The physiotherapists who were excluded from this study were as follows: 35 who were inactive members, 16 of whom were involved in teaching and research, 3 home care physiotherapists, 2 honorary members, 2 in private practice working as bone-setters and 1 graduate student.

The design of this study was cross-sectional. Following translation of the original English version of the questionnaire into Japanese, physiotherapists in the University of Kanazawa Hospital's Department of Physical Therapy critically examined the Japanese version for its wording and phrasing. Surveys were mailed to the individual respondents with a letter of explanation concerning the purpose of the study, together with a stamped addressed envelope. The returned questionnaires were anonymous. 
The instructions to respondents included a guarantee of confidentiality, the need to respond to every item and the absence of a right or wrong answer. The survey took approximately 15 minutes to complete.

One hundred and eighty-two questionnaires were collected without any reminder being necessary, with only one respondent declining to participate. Accordingly, the sample for statistical analyses consisted of $181(57.6 \%)$ respondents with the number of women being 101 and men 80 . The average (SD) experience of the respondents' clinical practice was 8.9 (7.3), ranging from 0.5 to 37.0 years. The number (percentage) of the respondents who were living with the elderly at the time of the study was 34 (18.9), those who had lived with the elderly in the past 84 (46.7) and those with no cohabitation experience with them 62 (34.4), respectively (One respondent did not indicate whether or not he/she had had cohabitation experience with the elderly).

\section{Statistics}

For all of the following statistical analyses, the scores for $\mathrm{E}^{-}$were reversed; i.e., from the score of 1 to the score of 7 and from the score of 7 to the score of 1 . The lowest possible score attainable was 34 and the highest 238. Reliability was assessed as correlations between the scores for each item and the whole scale using Spearman's rank correlation coefficient. This was followed by the calculation of the Cronbach's $\alpha$ reliability estimates for the internal consistency of the whole scale, $\mathrm{E}^{+}$and $\mathrm{E}^{-}$, respectively. As for construct validity, responses to 34 items were submitted to a factor analysis; in this case, a principal component analysis with varimax rotation. The number of factors was determined by using the factor scree plot. An attempt was also made to address convergent validity using multiple regression analysis for the amount of clinical practice, gender and cohabitation with the elderly as independent variables. Dependent variables were the total scale, $\mathrm{E}^{+}$scale, and $\mathrm{E}^{-}$scale, respectively.

The data were analysed at the 0.05 alpha level with the Statistical Package for the Social Sciences (SPSS, version 11.0J for Windows 2000).

\section{RESULTS}

\section{Reliability}

The homogeneity of the scale is displayed in
Table 1 showing correlations between each item and the total scale. The correlation coefficients for all of the items were statistically significant at $\mathrm{p}<0.01$. The number of items with a correlation coefficient larger than 0.4 was 12 in $\mathrm{E}^{-}$and 12 in $\mathrm{E}^{+}$, respectively. Cronbach's $\alpha$ was 0.87 for the total scale, 0.86 for $\mathrm{E}^{+}$and 0.85 for $\mathrm{E}^{-}$. In addition, Cronbach's $\alpha$ for Factors 1, 2 and 3, as described were $14.0,8.7$ and 8.0, respectively.

\section{Validity}

Construct validity was, to some degree, supported in the factor analysis, where the three factors could be interpreted in a meaningful way. In the secondorder factor analysis these factors explained $30.7 \%$ of the variances (Table 2). Factor 1 (labelled Prejudice) consisted of only $\mathrm{E}^{-}$items explaining $14.0 \%$ of the variances in the second-order factor analysis. Factors 2 (labelled Appreciation) and 3 (labelled Expectation) consisted of only $\mathrm{E}^{+}$items explaining $8.7 \%$ and $8.0 \%$, respectively, of the variances in the second-order factor analysis.

As for the result of the multiple regression analysis, the coefficient of determination $\left(\mathrm{R}^{2}\right)$ for the amount of clinical practice, gender and cohabitation with the elderly was 0.008 , which precluded our ability to examine the evidence of convergent validity.

\section{DISCUSSION}

Although the Spearman's rank correlation coefficients for all of the items yielded statistical significance, weakly correlated items $(<0.3)(1 \mathrm{~N}$, $7 \mathrm{~N}, 9 \mathrm{P}, 11 \mathrm{P}$ and $17 \mathrm{P}$ ) could not be evaluated due possibly to the relatively large sample size. Accordingly, visual inspection of scattergrams (not shown) of the aforementioned items demonstrated hardly any association between the score for each item and that for the whole scale. Two of these items $(1 \mathrm{~N}$ and $7 \mathrm{~N})$ were statements concerning the status of the elderly in society. The small correlation coefficient for 17P might have been due to the possible difficulty in the understanding of the item on the part of the respondents. Therefore, its meaning of dependency might not have been reflected in their response. The score for each of these items with a weak correlation and that for the total scale yielded small correlation coefficients. However, an increase in the value of Cronbach's $\alpha$ was within a range of less than 0.1 when non- 
Table 1. Spearman's rank correlation coefficients between the items and the total scale $(n=181)$

\begin{tabular}{|c|c|c|}
\hline Item & Main item content & $\mathrm{R}_{\mathrm{s}}$ \\
\hline $1 \mathrm{~N}$ & The elderly should live in special residences. & 0.218 \\
\hline $2 \mathrm{~N}$ & The elderly are different. & 0.367 \\
\hline $3 \mathrm{~N}$ & The elderly are unable to change. & 0.461 \\
\hline $4 \mathrm{~N}$ & The elderly quit work when they become pensioners. & 0.426 \\
\hline $5 \mathrm{~N}$ & The elderly have shabby homes. & 0.409 \\
\hline $6 \mathrm{~N}$ & Wisdom does not come with advancing age. & 0.368 \\
\hline $7 \mathrm{~N}$ & The elderly have too much influence in society. & 0.266 \\
\hline $8 \mathrm{~N}$ & The elderly make others feel ill at ease. & 0.463 \\
\hline $9 \mathrm{~N}$ & The elderly bore others with their stories. & 0.551 \\
\hline $10 \mathrm{~N}$ & The elderly are always prying into the affairs of others. & 0.499 \\
\hline $11 \mathrm{~N}$ & The elderly have irritating faults. & 0.520 \\
\hline $12 \mathrm{~N}$ & The elderly have a negative input on a neighbourhood. & 0.447 \\
\hline $13 \mathrm{~N}$ & The elderly are much alike. & 0.399 \\
\hline $14 \mathrm{~N}$ & The elderly are untidy. & 0.492 \\
\hline $15 \mathrm{~N}$ & The elderly are irritable, grouchy and unpleasant. & 0.443 \\
\hline $16 \mathrm{~N}$ & The elderly complain about the young. & 0.511 \\
\hline $17 \mathrm{~N}$ & The elderly have excessive demands for love. & 0.483 \\
\hline $1 \mathrm{P}$ & The elderly should live integrated with the young. & 0.364 \\
\hline $2 \mathrm{P}$ & The elderly are not different from anybody else. & 0.477 \\
\hline $3 \mathrm{P}$ & The elderly are capable of new adjustments. & 0.488 \\
\hline $4 \mathrm{P}$ & The elderly prefer to work as long as they can. & 0.556 \\
\hline $5 \mathrm{P}$ & The elderly have clean, attractive homes. & 0.582 \\
\hline $6 \mathrm{P}$ & The elderly grow wiser with advancing age. & 0.413 \\
\hline $7 \mathrm{P}$ & The elderly should have more power in society. & 0.529 \\
\hline $8 \mathrm{P}$ & The elderly are relaxing to be with. & 0.428 \\
\hline 9P & It is nice when the elderly tell about their past. & 0.286 \\
\hline $10 \mathrm{P}$ & The elderly mind their own business. & 0.526 \\
\hline $11 \mathrm{P}$ & The elderly have the same faults as the young. & 0.231 \\
\hline $12 \mathrm{P}$ & Neighbourhood is nice when integrated with the elderly. & 0.434 \\
\hline $13 \mathrm{P}$ & The elderly are different from one another. & 0.366 \\
\hline $14 \mathrm{P}$ & The elderly are clean and neat. & 0.511 \\
\hline $15 \mathrm{P}$ & The elderly are cheerful, agreeable and good-humoured. & 0.469 \\
\hline $16 \mathrm{P}$ & The elderly seldom complain about the young. & 0.434 \\
\hline 17P & The elderly need no more love than others. & 0.192 \\
\hline
\end{tabular}

correlated items were excluded. Therefore, the decision was made not to exclude these items from the analysis.

Out of eight items showing a relatively strong correlation $(>0.5)$, the respondents were very likely to have encountered four $(9 \mathrm{~N}, 11 \mathrm{~N}, 16 \mathrm{~N}$ and $4 \mathrm{P})$ of them during interaction with the elderly in clinical practice. Because $5 \mathrm{P}$ and $14 \mathrm{P}$ showed a relatively strong correlation, those respondents, who considered the elderly to be clean, had a positive view about them. As for $7 \mathrm{P}$, due to a weak correlation for $7 \mathrm{~N}$, ATE is much more likely to have been influenced by the respondents' high expectation of the elderly in society.

An acceptable reliability coefficient ranges from
0.50 to $0.95^{8)}$ depending on factors such as number and type of items, variability in the sample, and testing procedures ${ }^{9}$. The Japanese version in this study yielded larger Cronbach's $\alpha$ than the Swedish version; i.e. 0.79 for the total scale, 0.65 for $\mathrm{E}^{+}$and 0.82 for $E^{-7)}$. This fact, as well as the dearth of competing reliability measures currently available, suggests that the Japanese version can be considered adequate for testing of ATE of the current study group.

The results reflected both positive and negative sentiments towards the elderly. Prejudice (Factor 1) dealt solely with negative sentiments and Appreciation (Factor 2) solely with positive sentiments. Those items for Expectation (Factor 3) 
Table 2. Factor loadings after varimax rotation for the ATE scale

\begin{tabular}{rccc}
\hline Item & $\begin{array}{c}\text { Factor 1 } \\
\text { Prejudice }\end{array}$ & $\begin{array}{c}\text { Factor 2 } \\
\text { Appreciation }\end{array}$ & $\begin{array}{c}\text { Factor 3 } \\
\text { Expectation }\end{array}$ \\
\hline $17 \mathrm{~N}$ & 0.667 & & \\
$15 \mathrm{~N}$ & 0.644 & & \\
$12 \mathrm{~N}$ & 0.630 & & \\
$14 \mathrm{~N}$ & 0.601 & & \\
$8 \mathrm{~N}$ & 0.568 & & \\
$11 \mathrm{~N}$ & 0.545 & & \\
$10 \mathrm{~N}$ & 0.493 & & \\
$16 \mathrm{~N}$ & 0.481 & & \\
$5 \mathrm{~N}$ & 0.464 & & \\
$9 \mathrm{~N}$ & 0.451 & & \\
$4 \mathrm{~N}$ & 0.449 & & \\
\hline $15 \mathrm{P}$ & & 0.689 & \\
$14 \mathrm{P}$ & & 0.651 & \\
$16 \mathrm{P}$ & & 0.555 & \\
$10 \mathrm{P}$ & & 0.545 & 0.74 \\
$17 \mathrm{P}$ & & 0.416 & 0.453 \\
$5 \mathrm{P}$ & & 0.414 & 0.442 \\
\hline 4P & & & \\
$12 \mathrm{P}$ & & & \\
$7 \mathrm{P}$ & & 0.77 & \\
$8 \mathrm{P}$ & & & \\
$9 \mathrm{P}$ & & & \\
\hline Contribution $(\%)$ & 14.0 & & \\
Cronbach's $\alpha$ & 0.84 & & \\
\hline
\end{tabular}

that demonstrated a relatively strong correlation were $4 \mathrm{P}, 7 \mathrm{P}, 8 \mathrm{P}, 9 \mathrm{P}$ and $12 \mathrm{P}$, dealing solely with positive sentiments and not overlapping with Appreciation. Thus, Factor 3 denotes the potential capacity of the elderly in Expectation. Convergent validity for the instrument could not be verified.

\section{Limitations}

One limitation of this study was the relatively low response rate $(57.6 \%)$ of the respondents, and also physiotherapists from only one out of 47 prefectures were studied. In addition, because the data were collected anonymously, it is not known if this sample would differ from the ones who did not respond.

Further study may include examination of convergent validity using different criteria other than those used in this study.

\section{ACKNOWLEDGEMENTS}

The authors express gratitude to the members of the Ishikawa Physical Therapy Association for their participation in this study.

\section{REFERENCES}

1) Population Statistics by the Ministry of the Interior. Hokkoku Newspaper, 15 Aug. 2003, 1 (in Japanese).

2) Tuckman J, Lorge I: Attitudes toward old people. J Soc Psych, 1953, 37: 249-260.

3) Eisdorfer C, Altrocchi J: A comparison of attitudes toward old age and mental illness. J Gerontol, 1961, 21: 455-457.

4) Kogan N: Attitudes toward old people: the development of a scale and an examination of correlates. J Abnorm Soc Psychol, 1961, 64: 44-54.

5) Söderhamn O, Lindecrona C, Gustavsson SM: Attitudes toward older people among nursing students and registered nurses in Sweden. Nurs Educ Today, 2001, 21: 225-229.

6) Ogiwara S, Morishima T, Mitsumura M: Attitudes 
towards the elderly: a comparison amongst health science and non-health science students. J Tsuruma Health Sci Soc Kanazawa Univ, 2004, 27: 135-141.

7) Söderhamn O, Gustavsson SM, Lindecrona C: Reliability and validity of a Swedish version of Kogan's old people scale. Scand J Caring Sci, 2000, 14: 211-215.
8) Ary D, Jacobs LC, Razavieh A: Introduction to Research in Education, 5th ed. Fort Worth: Harcourt Brace College Publishers, 1996, pp 283-287.

9) Shaughnessy JJ, Zechmeister EB: Research Methods in Psychology, 4th ed. Boston: McGraw Hill, 1997, pp $127-130$ 